define and remove the unstable fragment, which presumably causes the symptoms, while leaving in place the remainder of the meniscus to continue its protective function.

The problem still remains, why some meniscal lesions cause symptoms and others do not; which to excise and which to leave alone. The evidence, from the three papers cited above, supports a simple and conservative policy. In the two clinical reports the indications for surgery were clear-cut : the patients had symptoms of a mechanical derangement, intermittent locking, and painful clicks and clunks or the sensation of something moving in the knee. Arthroscopy revealed unstable tears, in which the fragments were displaced, or could be displaced, from the remainder of the meniscus. Removal of the unstable fragment relieved the symptoms in nearly every case. The post-mortem studies suggest that, in the population at large, unstable lesions of this type are relatively uncommon and that, unlike the more frequently encountered degenerative lesions, they may occasion osteoarthritic changes in the adjacent joint surfaces.

The surgeon who limits his practice of meniscectomy to the removal of demonstrably unstable fragments from the knees of patients with symptoms of an internal derangement can, therefore, be sure of doing much good and very little harm. It is difficult to justify more radical excisions or less precise indications.

It seems that the arthroscopic method is the most convenient for the patient and, in skilled hands, may offer the best chance of conserving useful meniscal cartilage. However, the indications for meniscectomy have quite properly diminished as our knowledge of the knee joint has increased and it would be a pity if the liberty to operate by closed methods should be misinterpreted as a licence to operate too often.

J. W. GOODFELLOW

J. W. Goodfellow, MS, FRCS, Consultant Orthopaedic Surgeon, Nuffield Orthopaedic Centre, Headington, Oxford OX3 7LD, England.

\title{
REFERENCE
}

Fahmy NRM, Williams EA, Noble J. Meniscal pathology and osteoarthritis of the knee. J Bone Joint Surg [Br] 1983:65-B:24-8.

\section{TOURNIQUET PARALYSIS}

The report of Aho et al. (pages 441 to 443 of this issue) adds to a growing list of similar examples of tourniquet paralysis. To avoid further episodes of this nature it is important to study the problem in the light of our knowledge of the effects of a tourniquet on a limb; these result from pressure at the site of the cuff and from ischaemia distal to it.

Tourniquet paralysis due to a pneumatic cuff has been clearly shown by Professor Gilliatt and his coworkers to be the result of pressure substantially greater than the systolic blood pressure (Fowler, Danta and Gilliatt 1972). The distribution of damage along the nerve differs from that which follows ischaemia; there is evidence of mechanical deformation of the nerve fibres with displacement of the nodes of Ranvier and distortion of the paranodal myelin (Ochoa, Fowler and Gilliatt 1972). A characteristic of these lesions is the relatively short duration of compression required to produce them. Rudge, Ochoa and Gilliatt (1974) managed to produce a demyelinating block in the anterior tibial nerve of the baboon in one hour. With the majority of operative procedures the tourniquet time is unlikely to exceed two or three hours, a period which has been shown to be within the margins of safety for producing irreversible damage to muscle, the tissue most vulnerable to prolonged deprivation of blood (Patterson and Klenerman 1979; Klenerman et al. 1980). In the words of Sir Thomas Lewis (1946), "the nerves of the limbs lose their function under ischaemic conditions long before the muscle becomes inexcitable, but long-continued ischaemia kills muscle more readily than it kills nerves." He also said, "if a narrow band or cord is tied very tightly round a limb, it may directly damage the main nerves."

The incidence of nerve palsies associated with the use of a tourniquet is 1:8000, based on a survey of members of the Australian Orthopaedic Association (Middleton and Varian 1974). Paralysis was most common in the upper limb and in 50 per cent of cases involved median, ulnar and radial nerves. All the examples which affected the lower limb were associated with the use of an Esmarch's bandage as a tourniquet, a practice which should be discontinued. However, use of the pneumatic tourniquet has been reported to have resulted in five examples of paralysis in a series of patients undergoing knee ligament reconstruction (Rorabeck and Kennedy 1980); in four of these patients the lateral popliteal nerve only was affected.

Examples of faulty gauges which have resulted in nerve palsy are numerous (Wheeler and Lipscomb 1964; Hamilton and Sokoll 1967; Bruner 1970; Prevoznik 1970; Calderwood and Dickie 1972; Durkin and Crabtree 1982). It is essential that pneumatic tourniquets are regularly checked by testing the gauges against a mercury manometer. Flatt (1972) recommended that this be done at the start of each operating session and it is certainly a simple and quick procedure. Such checking will not by itself ensure complete safety. The pressure applied should always be related to the patient's blood pressure as recorded on arrival in the anaesthetic room. For the upper limb the pressure required need be no more than 
50 millimetres of mercury above the systolic pressure (to allow for fluctuations which may occur during the course of an operation). For the lower limb, where the cuff often has to be relatively narrow to permit adequate surgical access, twice the systolic pressure is sufficient provided the patient is not unduly muscular or obese (Klenerman and Hulands 1979). The pressure used should be recorded on the anaesthetic chart together with the times of application and release of the tourniquet. Special care is necessary for thin patients, and padding should be applied to protect the limb beneath the tourniquet. A tired assistant must not inadvertently rest on the cuff, since this may significantly raise the pressure applied. The gauge of the tourniquet should be inspected by a vigilant anaesthestist during the course of the operation and he should ensure that the pressure remains constant; on deflation it should be noted whether or not the dial indicator returns to zero.

The suggestion by Wheeler and Lipscomb (1964)

that the rocker valve of an ordinary pressure cooker should be inserted between the tourniquet gauge and the cuff has much to commend it, as it will not allow a predetermined upper limit of pressure to be exceeded. This pattern of safety valve is an integral part of every anaesthetic apparatus. A simple hand pressure pump with an accurate gauge is safer and preferable to more sophisticated and expensive tourniquets which may be inaccurate; at least the person using the pump knows by feel how hard he has to press to inflate the cuff and does not simply turn a switch unthinkingly. Nor should we forget that it is perfectly possible to operate without a tourniquet by suitable positioning of the limb.

The pneumatic tourniquet, common everyday instrument as it is, should not merely be taken for granted; it should be used with due consideration for the physiology of the limb to which it is applied, and with the same respect for pressure as for time.

\section{KLENERMAN}

L. Klenerman, ChM, FRCSEd, FRCS, Consultant Orthopaedic Surgeon, Northwick Park Hospital, Watford Road, Harrow, Middlesex HAI 3UJ, England.

\section{REFERENCES}

Bruner JM. Time, pressure, and temperature factors in the safe use of the tourniquet. Hand 1970;2:39-42.

Calderwood JW, Dickie WR. Tourniquet paresis complicating tendon grafting. Hand 1972;4:53-5.

Durkin MAP, Crabtree SD. Hazard of pneumatic tourniquet application. Proc R Soc Med 1982; 75:658-60.

Flatt AE. Tourniquet time in hand surgery. Arch Surg 1972;104:190-2.

Fowler TJ, Danta G, Gilliatt RW. Recovery of nerve conduction after a pneumatic tourniquet: observations on the hindlimb of the baboon J Neurol Neurosurg Psychiatry 1972:35:638-47.

Hamilton WK, Sokoll MD. Tourniquet paralysis. JAMA 1967:199: 37.

Klenerman L, Hulands GH. Tourniquet pressures for the lower limb. J Bone Joint Surg [ Br] 1979;61-B: 124

Klenerman L, Biswas M, Hulands GH, Rhodes AM. Systemic and local effects of the application of a tourniquet. J Bone Joint Surg [Br] 1980; 62-B: $385-8$

Lewis Sir T. Vascular disorders of the limbs. 2nd ed. New York: Macmillan Company 1946:21-2.

Middleton RWD, Varian JP. Tourniquet paralysis. Aust NZ J Surg 1974:44:124-8.

Ochoa J, Fowler TJ, Gilliatt RW. Anatomical changes in peripheral nerves compressed by a pneumatic tourniquet. J Anat 1972:113:433-55.

Patterson S, Klenerman L. The effect of pneumatic tourniquets on the ultrastructure of skeletal muscle. J Bone Joint Surg [Br] 1979;61-B: 178-83. Prevoznik SJ. Injury from use of pneumatic tourniquets. Anesthesiology 1970;32:177.

Rorabeck CH, Kennedy JC. Tourniquet-induced nerve ischemia complicating knee ligament surgery. Am J Sports Med 1980;8:98-102.

Rudge P, Ochoa J, Gilliatt RW. Acute peripheral nerve compression in the baboon. J Neurol Sci 1974;23:403-20.

Wheeler DK, Lipscomb PR. A safety device for a pneumatic tourniquet. J Bone Joint Surg [ Am] 1964:46-A :870.

\section{ANNOTATION}

\section{ULTRA-CLEAN AIR}

The British Medical Journal, volume 285, published a report from the Medical Research Council giving the results of its randomised trial of ultra-clean air systems of theatre ventilation, compared with a control of standard theatre environments (Lidwell et al. 1982). This paper has been anticipated with eagerness and anxiety by all who are concerned with theatre asepsis, most particularly by those involved in major joint replacement.

Charnley believed, with justification, that the mechanical problem with regard to hip disease was solved and that the only threat to successful arthroplasty was infection. He remained profoundly absorbed, not to say obsessed, with the prospect of providing a germ-free environment for the operation. Although Buchholz and others have demonstrated that infection need not necessarily be an unmitigated disaster, nevertheless it remains the principal threat to successful surgery and certainly leads to prolonged morbidity with repetitive revision operations. Charnley's observations led to the conclusion that the provision of clean air in the operating environment was an obligation upon everyone involved in this form of surgery. Few things concentrate the 